\title{
Chapter 6 \\ Regarding Measures by Rural Areas \\ to Promote Migration and Settlement \\ and Increase Associating \\ Populations-Implications from Various \\ Measures Triggered by Hometown Tax \\ Donation
}

Keywords Migration and settlement measures • Parenting support measures •

Regional revitalization $\cdot$ Interacting population $\cdot$ Associating population

\subsection{Sharing of People is Important Amid National Depopulation}

The circulation of people, goods and capital is important in revitalizing rural areas. Hometown Tax Donation gifts have forged a scheme where rural areas secure capital by providing goods to the Tokyo metropolitan area and other urban areas. Ideally, however, rural areas should promote local specialties in the gift market (i.e., capture recognition), then obtain consumers in regular markets (i.e., capture real demand), and finally attract people to their region. Depopulation is a major issue faced by rural areas, and many municipalities are actively promoting migration and settlement. However, enhanced migration and settlement measures and competition to win over residents by each municipality, amid depopulation projected on a national scale, will lead to a scenario where widespread zero-sum competition exhausts the entire country. Instead, emphasis should be placed on measures to increase associating populations. In other words, municipalities should aim to share people rather than secure residents.

As an example, in Kamiyama Town and Minami Town in Tokushima Prefecture, venture businesses have opened satellite offices in succession, bringing forth a lifestyle of working from both rural and urban areas-for instance, working from a satellite office for several months during the year and in the city for the rest. In addition, with the promotion of crowdsourcing and telework, people living in rural

This chapter is based on Hoda (2019) and Hoda and Kubo (2019) with some edits and additions. 
areas can now work with companies in the city, and are no longer bounded by physical workplace. The need to migrate from rural areas to urban areas in search for a job is becoming a thing of the past. In particular, now that work from home (WFH) has become the new norm amid the coronavirus pandemic, the population flow from urban to suburban or rural areas may be irreversible.

Also, in terms of tourism, minpaku, which involves renting out private property to tourists as represented by Airbnb, has become widespread, and ridesharing services such as Uber have also emerged. Against this backdrop, some regions are striving to increase associating population through Hometown Tax Donation. Several survey research have also revealed that many people want to visit the regions to which they made donations.

This chapter explores cases of initiatives aimed at creating associating or interacting populations and of migration and settlement measures triggered by Hometown Tax Donation, and examines their effectiveness and ensuing policy implications.

\subsection{Creating Associating and Interacting Populations Through Hometown Tax Donation}

\subsubsection{Encouraging Experience-Oriented Visits}

Fujiyoshida City in Yamanashi Prefecture invited those who donated 20,000 yen or more to a bus tour in October 2018. A bus was chartered for a one-day tour from Shinjuku, Tokyo, to Fujiyoshida City. This tour was unique because local high school students proposed the route and even took part as tour guides. While Fujiyoshida City lies at the base of Mount Fuji, it is not a famous sightseeing destination. Thus, the first step in coming up with the one-day tour route was to excavate and reconsider the region's attractiveness. The route included visits to gift providers, whom the high school students visited and interviewed in advance to better understand their products.

Through this process, the local high school students got to know their community better, and gained civic pride through receiving praise from tour participants for their efforts and the city itself. The city had carried out five similar tours targeting donors since 2017 , but all were organized by municipal staff. This time around, the initiative was stepped up by engaging local high school students for the first time.

According to a survey research targeting the participants, who were chosen by lottery, approximately half ( 26 out of 55 respondents) visited Fujiyoshida City for the first time. As for why they applied to the tour, 29, or more than half, replied "because the tour was offered as a special benefit." It seems not a few participants joined mainly because the tour was free; however, the tour attracted not only retired seniors but participants of all ages ranging from those in their 10s to 70s (with relatively many in their 40s and 50s). It is remarkable that those of the working generation were willing to spare one whole day to visit the city, albeit for free. 
While the survey reported that participants were highly satisfied, it is also noteworthy that to the question "Was anything lacking?" quite a few expressed their opinions along the lines of "Perhaps locals themselves do not understand the region' s attractiveness. They should deliver a stronger message" or "Promotions should be stepped up since the city is so attractive." I believe this holds true not only for Fujiyoshida City but also rural areas across Japan. Often times, something locals find insignificant is deemed attractive from a non-local perspective. Fujiyoshida City's initiatives offer much to learn for municipalities across Japan in terms of creating associating populations.

Other regions are similarly inviting donors to visit; for instance, Tamaki Town and 12 other municipalities in southern Mie Prefecture organized a two-day regional tour. Higashikawa Town in Hokkaido Prefecture also invites donors to visit the town and take part in a tree-planting activity. Preserving forests is important for the town, which does not have a public water supply system, and in effect, tree-planting not only offers visitors a unique experience but is also part of machizukuri (i.e., community development). Inviting non-locals to think about machizukuri rather than merely treating them as guests, and having them consider the region as their own is none other than sharing of people.

\subsubsection{Rural Areas Actively Approaching Donors}

Meanwhile, some rural municipalities are approaching urban areas to increase associating and interacting populations. For instance, Kamishihoro Town in Hokkaido Prefecture and Hirado City in Nagasaki Prefecture hold "Hometown Tax Donation Thanksgiving" in urban areas represented by the Tokyo and Kansai metropolitan areas. Donors can become familiar with the region, including through food tasting of gifts, sessions introducing the town, and consulting desks for migration. Such events are either organized independently by municipalities, or jointly by multiple municipalities through Hometown Tax Donation gift web portals or other platforms. Creating a point of actual contact should also prompt donors to make repeated donations.

\subsubsection{Creating Opportunities for Citizens to Participate in Machizukuri: Strengthening Local Kizuna}

While I introduced initiatives for increasing associating and interacting non-locals thus far, rural areas also face the troublesome issue of contraction and outflow of populations. Against this backdrop, there are cases where Hometown Tax Donation has served to strengthen the connection between municipalities and local residents. 
For example, Nemuro City in Hokkaido Prefecture and Sakai City in Fukui Prefecture contemplate the use of Hometown Tax Donations with local volunteers.

Normally, the municipal council determines the use of budgets, and therefore, citizens only indirectly engage in decision-making through the council member they elected. In reality, most citizens are uninterested in what goes on the council as well as machizukuri, and many do not feel attached to their town. Even if they are interested, both municipal and central governments in Japan are currently inclined toward so-called "silver democracy." Diet and municipal council members strive to gather votes from senior citizens, since those who vote consist mostly of senior citizens and the ratio of the elderly population is also on the rise. Accordingly, the diet and municipal councils prioritize discussions on and budget allocations to measures that benefit the silver generation.

On the other hand, Hometown Tax Donations are funds secured from outside the region, and therefore, their usage can be considered more flexibly and dynamically. Nemuro City invited applicants from the general public, mainly in their prime working years of $30 \mathrm{~s}$ or $40 \mathrm{~s}$ and with wide-ranging occupations, as members of the "Nemuro City Hometown Support Future Meeting," to discuss and propose the usage of donations. Uniquely, they also organized a sub-committee consisting solely of high school students. Such initiatives will spur locals' interest in machizukuri and enable discussions on regional issues that are difficult to attend to in a silver democracy. This should help strengthen local kizuna (i.e., bonding) and may even help suppress population outflow.

If the city takes this one step further and extends membership to donors of Hometown Tax Donation, ties with non-local interacting populations may also be strengthened further.

\subsection{How to Perceive Enhancement of Migration and Settlement Measures}

\subsubsection{Successful Cases Are Few on a National Scale}

The central government asks that each municipality create a "regional population vision" and "regional comprehensive strategies" in line with the basic principle of halting excessive concentration of population in Tokyo and resolving regional issues according to regional characteristics. The comprehensive strategy positions measures against depopulation as a major challenge in regional development, and as actual measures to generate population flow to rural areas, the government promotes "regional revitalization cooperation troops" which comprises citizens, and dual residence. In addition, each municipality deploys their own migration initiatives, with some actually yielding positive results_for example, "mild" migrations promoted by Sabae City in Fukui Prefecture, or the migration and startup support project by Nishiawakura Village in Okayama Prefecture. Such movements have generated a 
population inflow to rural areas, including of younger generations represented by ICT engineers or content creators who are more receptive to rural migration, and of senior citizens seeking continuing care retirement communities (CCRC) (Koyanagi 2016). However, the extent of new inflow to rural areas is still insufficient.

Yet, in this environment, some municipalities are anticipated to increase interacting populations or boost migration and settlement going forward driven by Hometown Tax Donation. A representative case is Kamishihoro Town in Hokkaido Prefecture, which was introduced as "having increased population through enhanced parenting support" in the best practices of Hometown Tax Donation usage compiled by the MIC in 2018 .

\subsubsection{Effects and Pros and Cons of Enhanced Parenting Support Measures}

Kamishihoro Town, with a population of merely 5000, collected 970 million yen in Hometown Tax Donations in 2014 (ranked no. 3 nationwide) owing to its popular gift of naitai Japanese beef. This prompted them to establish "The Ordinance for Kamishihoro Town Hometown Tax Donation and Dream Fund for Parenting Support and Measures Against Declining Birth Rate," and allocate all donations to this fund for the purpose of enhancing parenting support measures. For example, donations were used to purchase a school bus and to make the tuition for Nintei Kodomoen Horon, an integrated center for early childhood education and care in Kamishihoro Town, partly free in 2015, and completely free for a decade starting from 2016.

At Horon, the municipality also financially aids English lessons taught by foreign teachers and transport for children commuting long distances. The town's initiatives have been covered by multiple national media, and the town has increasingly been introduced as a successful case of using Hometown Tax Donations to enhance parenting support measures and raise its population. As an example, a Nihon Keizai Shimbun article dated June 15, 2016 reported that "Kamishihoro Town in Hokkaido Prefecture, which receives one of the largest donations nationwide, used donations to open a nintei kodomoen with integrated functions of both nursery center and kindergarten, and made the tuition partly free in fiscal year 2015. The town's population, which had been declining, increased by 40 people during the four months between February and May."

While there are not a lot of prior studies on how parental support measures influences migrations, Nakazawa et al. (2015) analyzed the impact that municipal parental support measures have on birth rates and migrations of households with small children, targeting municipalities across Japan and in the Tokyo metropolitan area. Results showed that in the Tokyo metropolitan area, parenting support measures are a contributing factor for parents with small children to move from other municipalities, and notably, that having sufficient nursery centers distinguishes municipalities with many child-raising households from those without. However, this trend was not 
apparent in the analysis targeting municipalities across Japan. The study also pointed out that "it is necessary to examine whether municipal parenting support measures are truly effective" in light of the revelation that migrations of children aged five to nine were influenced by the presence of opportunities to receive higher education, but not by income support offered as part of children welfare expense.

With regards to migrations from rural to urban areas, it was revealed that migrants place importance on living environment in cases of both U-turns, where people return to places they lived in the past, and J-turns or I-turns, where people move to new places (e.g., Abe et al. 2010, Komori 2008, and Sakuno 2016). Also, Lee and Sugiura (2017) have revealed in a research targeting migrants to Hirosaki City in Aomori Prefecture, that many of the migrations were homecomings by ex-residents, and that the major determinant for migrations was the presence of parents' homes as places of residence. Therefore, promoting migrations presumably requires enriching living environments in addition to enhancing parenting support measures.

Analysis results of Nakazawa et al. imply that although enhanced parenting support measures, especially enriching nursery centers, influence migrations in the Tokyo metropolitan area, careful analysis and judgement are required considering the long-term burden on public finance, and that thorough discussion is required on enhancing parenting support measures with the purpose of promoting migrations, since such measures do not necessarily have an impact on migrations at the national level. It should be noted that Nakazawa et al. did not analyze the origin and destination of migrations, and therefore, it is unclear whether migrations are mainly from neighboring municipalities or from distant regions. However, as is discussed in their thesis, better contents and levels of parenting support measures most likely prompt migrations from neighboring municipalities. Work is a major restraint particularly for rural migration, and it is easy to imagine that urban residents who have trouble finding nursery center vacancies may not be able to migrate to rural areas even if they want to, because of work. On the other hand, they can migrate to neighboring municipalities while keeping their job.

This means that in rural areas, enhanced parenting support measures by a municipality may lead to an unproductive race to win over households with small children among neighboring municipalities that also face depopulation. The return of populations from urban to rural areas would be desirable if it alleviates concentrated population in Tokyo; however, rural municipalities already exhausted with depopulation must avoid further mutual exhaustion through scrambling for residents with neighboring municipalities.

The discussions above lead to the hypothesis that enhancing parenting support measures financed by Hometown Tax Donations (1) causes neighboring rural municipalities to compete for residents. In addition, since the spread of telework mitigates the restraining factor of work in migration and settlement, it is also possible to hypothesize that such measures (2) promote migrations from urban to rural areas. In particular, donations to one's hometown may trigger U-turn migrations. As for settlement, it can be hypothesized that such measures (3) suppress outflow of the child-raising generation. 
I verified these hypotheses by analyzing the case of Kamishihoro Town in Hokkaido Prefecture. Since this is an analysis of a single case, results cannot be generalized; however, they should serve as reference in determining whether respective municipalities should enhance parenting support measures using Hometown Tax Donations.

\subsection{Demographic Analysis of Kamishihoro Town, Hokkaido Prefecture}

\subsubsection{Analysis Method}

Ideally, the analysis should also include impacts by measures other than parenting support; however, according to an interview with the municipality, no major changes were made in other measures during the period subject to the analysis, and therefore, the impact of enhanced parenting support measures is presumed to have been dominant.

First, I verified the town's demographic data between 2012 and 2017 from the Basic Resident Register to clarify the breakdown of the rise in population. Kamishihoro Town falls under the jurisdiction of Tokachi General Subprefectural Bureau, whose economic activities are centered around Obihiro City and Otofuke Town, and therefore, Kamishihoro Town's population is susceptible to outflows to and inflows from these two municipalities. In addition, Shihoro Town lies between these two municipalities and Kamishihoro Town; thus, if enhanced parenting support measures by Kamishihoro Town have a large impact on surrounding regions, it should translate to migrations to and from these three municipalities. Meanwhile, if enhanced parenting support measures by Kamishihoro Town influence migrations to and from distant regions, this should translate to change in number of migrations to and from regions other than these three municipalities. I therefore conducted the analysis by dividing these three surrounding regions from the other regions. I first analyzed the change in number of people moving to and from Kamishihoro Town while defining those under the age of 40 as the "child-raising generation," and as a supplement, also analyzed results of a survey targeting those who moved to the town.

On a side note, Kamishihoro Town lies $38 \mathrm{~km}$ north of Obihiro City, which has a population of nearly 170,000, and is $70 \mathrm{~km}$ from Tokachi Obihiro Airport. The town is famous for wheat, beans, potatoes, and sugar beets, and its main industries are agriculture, forestry, and dairy (Fig. 6.1). 


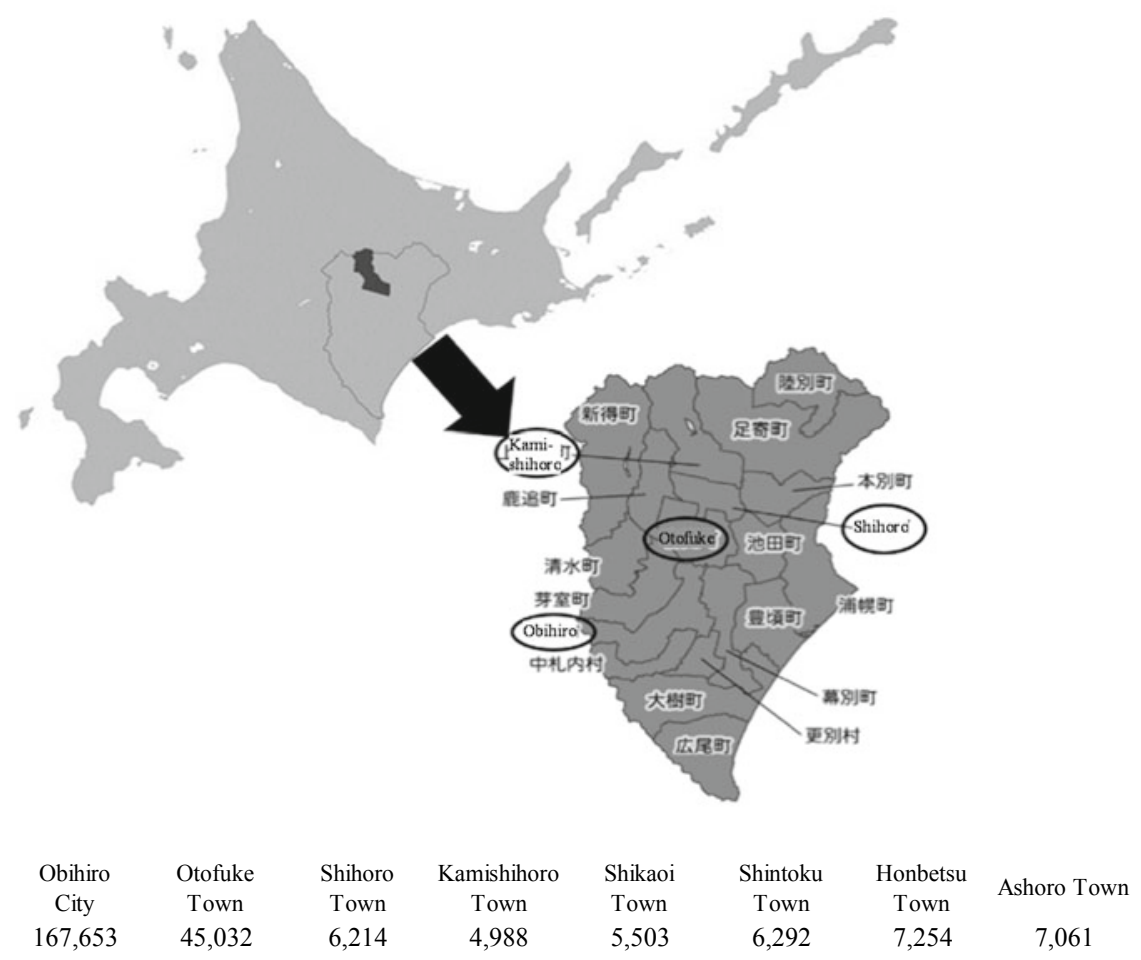

Fig. 6.1 Peripheral map of Kamishihoro Town and population data (no. of people). Note Kamishihoro Town and the three surrounding regions are circled. Source Created by the author based on Kamishihoro Town's website, Tokachi General Subprefectural Bureau's website, and the 2018 Basic Resident Register by the MIC

\subsubsection{Trend in Population Change of Kamishihoro Town, Hokkaido Prefecture}

Figure 6.2 shows the historical trend in number of people moving to and from Kamishihoro Town. The natural population change shows no major change in number of births, implying that parenting support measures are not yet spurring a rise in number of births. Meanwhile, social population change has shifted to an increase from 2015. There was both an increase in people moving in and decrease in people moving out. The town's social population change for migrations within Japan was $0.06 \%$ in 2015, achieving a large leap in ranking among the 179 municipalities in Hokkaido Prefecture, and ranking in first place in 2016 and 2017. 


\begin{tabular}{ccrrrrrr} 
& & \multicolumn{1}{c}{ CY2012 } & CY2013 & CY2014 & CY2015 & CY2016 & CY2017 \\
\cline { 3 - 8 } $\begin{array}{c}\text { Natural } \\
\text { population } \\
\text { change }\end{array}$ & Births & 37 & 37 & 37 & 25 & 32 & 36 \\
& Deaths & 75 & 76 & 68 & 79 & 73 & 63 \\
\cline { 2 - 8 } & Total & -38 & -39 & -31 & -54 & -41 & -27 \\
$\begin{array}{c}\text { Social } \\
\text { population } \\
\text { change }\end{array}$ & Move in & 234 & 256 & 178 & 225 & 258 & 303 \\
& Move out & 295 & 285 & 265 & 222 & 192 & 222 \\
\cline { 2 - 8 } & $\begin{array}{c}\text { Total } \\
\text { Social population } \\
\text { percent change } \\
\text { (rank in }\end{array}$ & $-1.21 \%$ & $-1.24 \%$ & $-1.78 \%$ & $0.06 \%$ & $1.36 \%$ & $1.65 \%$ \\
& $(143$ th) & $(65$ th) & $(175$ th) & $(22$ nd) & $(1 \mathrm{st})$ & $(1 \mathrm{st})$ \\
& Hokkaido) & & & & & & \\
$\begin{array}{c}\text { Population } \\
\text { change }\end{array}$ & Social + natural & -99 & -68 & -118 & -51 & 25 & 54
\end{tabular}

Fig. 6.2 Trend in population of Kamishihoro Town. Note Social population change $=$ (no. of people moving to Kamishihoro Town + no. of people moving from Kamishihoro Town)/total population of Kamishihoro Town. Note that only people moving within Japan are included (i.e., people moving to and from other countries are excluded). Note Created by the author from data on population, demographics and no. of households (by municipality, for Japanese residents) based on the Basic Resident Register by the MIC.

\subsubsection{Trend in Number of People Moving to Kamishihoro Town, Hokkaido Prefecture}

Next, I verified the breakdown of people moving to Kamishihoro Town by region of origin (Fig. 6.3). People moving to Kamishihoro Town consisted mostly of those from other regions within Hokkaido, with those from the three surrounding regions increasing drastically from 66 in 2015 to 93 in 2016. In 2016, those who moved from the three surrounding areas accounted for $36.2 \%$ of all people moving in. In addition, the number of people moving from urban areas (i.e., Tokyo, Kanagawa, Osaka, Chiba and Saitama prefectures) with insufficient nursery center capacities increased to 39 in 2015 and 38 in 2016. In 2017, while the number of people moving from the three surrounding areas and urban areas settled down, the increase in number of people moving from prefectures excluding Hokkaido and the above urban prefectures was significant, with over a twofold increase from 29 in the previous year to 64. This increase is also considerable relative to data of the prior five years.

While interpretation requires care since the absolute numbers are not large, if such trends are the result of enhanced parenting support measures by Shihoro Town, numbers may have been pushed up by people moving from the three surrounding regions who were attracted to such measures in 2015 and 2016, but may have settled in 2017 once such potential migrants were successfully secured. Meanwhile, it can also be interpreted that people moving from other regions across Japan increased in 2017 after a slight time lag owing to national media coverage of the town's initiatives in 2015 and 2016. Perhaps those who made Hometown Tax Donations in the past migrated to the town as well (especially U-turns). Kamishihoro Town has been 
CY2012 CY2013 CY2014 CY2015 CY2016 CY2017

\begin{tabular}{|c|c|c|c|c|c|c|}
\hline \multicolumn{7}{|l|}{ Hokkaido } \\
\hline Obihiro City & 46 & 52 & 30 & 42 & 51 & 31 \\
\hline Otofuke Town & & & & 14 & 31 & 30 \\
\hline Shihoro Town & 14 & & & & 11 & \\
\hline Total of 3 surrounding regions & 60 & 52 & 30 & 66 & 93 & 61 \\
\hline Sapporo City & 23 & 28 & 22 & 18 & 19 & 23 \\
\hline Other municipalities & 102 & 123 & 79 & 90 & 78 & 124 \\
\hline Total of Hokkaido & 185 & 203 & 131 & 164 & 190 & 208 \\
\hline Tokyo & 3 & 12 & 11 & 12 & 15 & 12 \\
\hline Kanagawa & 1 & 4 & 10 & 6 & 5 & 7 \\
\hline Osaka & 2 & 3 & 4 & 9 & 5 & 4 \\
\hline Saitama & 2 & 5 & 1 & 9 & 4 & 6 \\
\hline Chiba & 1 & 4 & 3 & 3 & 9 & 3 \\
\hline 5 metropolitan prefectures & 9 & 28 & 29 & 39 & 38 & 32 \\
\hline Other prefectures & 28 & 35 & 18 & 23 & 29 & 64 \\
\hline Total of outside Hokkaido & 46 & 91 & 76 & 101 & 105 & 128 \\
\hline Total & 222 & 256 & 178 & 226 & 257 & 304 \\
\hline$\%$ of 3 surrounding regions & $27.0 \%$ & $20.3 \%$ & $16.9 \%$ & $29.2 \%$ & $36.2 \%$ & $20.1 \%$ \\
\hline$\%$ of 5 metropolitan prefectures & $4.1 \%$ & $10.9 \%$ & $16.3 \%$ & $17.3 \%$ & $14.8 \%$ & $10.5 \%$ \\
\hline$\%$ of Hokkaido & $83.3 \%$ & $79.3 \%$ & $73.6 \%$ & $72.6 \%$ & $73.9 \%$ & $68.4 \%$ \\
\hline$\%$ of outside Hokkaido & $16.7 \%$ & $20.7 \%$ & $26.4 \%$ & $27.4 \%$ & $26.1 \%$ & $31.6 \%$ \\
\hline
\end{tabular}

Fig. 6.3 Trend in no. of people moving to Kamishihoro Town. Note The blank spaces for Otofuke Town and Shihoro Town do not indicate zero people. Since the MIC database only displays data for migrations of 10 or more people between municipalities, the blank spaces represent unavailable data for migrations of fewer than 10 people. Source Created by the author based on "Basic Resident Register Population Movement Report.”

holding "Hometown Tax Donation Thanksgiving" events in the Tokyo and Kansai metropolitan areas since 2015, and making actual contact with donors.

I focused on the age of people moving in to verify the above aspects. I defined those under the age of 40 as the "child-raising generation," and extracted data of such households as shown in Fig. 6.4.

This shows that the number of child-raising generation migrants from the three surrounding regions increased by more than twofold to 78 in 2016, with the childraising generation accounting for $83.9 \%$ of all people moving from the same regions,

\begin{tabular}{lrrrrrr} 
& $\mathrm{CY} 2012$ & $\mathrm{CY} 2013$ & $\mathrm{CY} 2014$ & $\mathrm{CY} 2015$ & CY2016 & CY2017 \\
\cline { 2 - 7 } 3 surrounding regions & 40 & 35 & 30 & 37 & 78 & 42 \\
$\%$ & $66.7 \%$ & $67.3 \%$ & $80.0 \%$ & $56.1 \%$ & $83.9 \%$ & $68.9 \%$ \\
Other regions & 121 & 148 & 95 & 120 & 127 & 181 \\
$\%$ & $74.7 \%$ & $72.5 \%$ & $64.2 \%$ & $70.6 \%$ & $77.4 \%$ & $74.5 \%$
\end{tabular}

Fig. 6.4 Trend in no. of child-raising generation migrants to Kamishihoro Town. Note The ratio represents the ratio of those under the age of 40 to all people moving to Kamishihoro Town from the respective regions. Source Created by the author based on "Basic Resident Register Population Movement Report." 


\begin{tabular}{|c|c|c|c|c|c|}
\hline \multirow{2}{*}{\multicolumn{3}{|c|}{$\begin{array}{l}\text { Attributes of Respondents } \\
\text { Age Group }\end{array}$}} & \multicolumn{3}{|l|}{ Migration style } \\
\hline & & & Unaccompanied & 226 & $84.0 \%$ \\
\hline $10 \mathrm{~s}$ & 12 & $4.5 \%$ & Accompanied by family & 43 & $16.0 \%$ \\
\hline $20 s$ & 122 & $45.4 \%$ & Total & 269 & \\
\hline $30 \mathrm{~s}$ & 67 & $24.9 \%$ & & & \\
\hline $40 \mathrm{~s}$ & 33 & $12.3 \%$ & Reason for moving & & \\
\hline $50 \mathrm{~s}$ & 10 & $3.7 \%$ & Work-related & 206 & $76.6 \%$ \\
\hline $60 \mathrm{~s}$ & 10 & $3.7 \%$ & Desire to live in Kamishihoro Town & 78 & $29.0 \%$ \\
\hline $70 \mathrm{~s}$ & 7 & $2.6 \%$ & Suitable housing & 76 & $28.3 \%$ \\
\hline $80 \mathrm{~s}$ & 8 & $3.0 \%$ & Quality child-raising and education environment & 32 & $11.9 \%$ \\
\hline \multirow[t]{5}{*}{ Total } & 269 & & Return to hometown & 28 & $10.4 \%$ \\
\hline & & & Free nursery fee & 24 & $8.9 \%$ \\
\hline & & & Extensive welfare measures & 22 & $8.2 \%$ \\
\hline & & & Other & 21 & $7.8 \%$ \\
\hline & & & Total & 269 & \\
\hline
\end{tabular}

Fig. 6.5 Results of a survey on reasons for moving to Kamishihoro Town. Note The survey targeted people who moved to Kamishihoro Town between August 2016 and July 2017 (no. of respondents $=269$ ). Source Created by the author based on results of a survey by Kamishihoro Town

the highest ratio during the prior five years. The timing is consistent with the enhancement in parenting support measures which started in 2015, implying that such enhancements most likely attracted the child-raising generation from the three surrounding regions. Meanwhile, a significant increase was seen in 2017 for the other regions.

I will also introduce results of a survey research conducted by Kamishihoro Town targeting people who moved to the town regarding reasons for migration, although the period of the research is slightly different (Fig. 6.5).

The survey targeted people who moved to Kamishihoro Town between August 2016 and July 2017 (no. of respondents $=269$ ). Attributes of respondents show that $75 \%$ belong to the child-raising generation under the age of 40 , consistent to data in Fig. 6.4. The breakdown indicates that 226 (84.0\%) moved unaccompanied, while $43(16.0 \%)$ moved accompanied by their family. Regarding the reason for moving, "work-related matters" was highest (76.6\%), followed by "desire to live in a rural area (Kamishihoro Town)" (29.0\%), and "suitable housing (or rented home)" $(28.3 \%)$. These top responses indicate that while the largest factor for the increase in population of Kamishihoro Town was work-related, living environment also holds a certain degree of significance. This is consistent with reports by prior studies on migration that living environment is important.

As for reasons related to parenting support measures, 32 respondents selected "quality child-raising and education environments" and 24 selected "free nursery fee." While ratios to all responses is not high, ratios to number of respondents who moved accompanied by their family, which was 43 , are $74 \%$ and $55 \%$ respectively, indicating that such factors have a large impact. Also, if a single person who moved to Kamishihoro Town for business reasons considers marriage or raising children 
in the future, some would presumably decide to stay in Kamishihoro Town with its extensive parenting support measures.

A study by Nakazawa et al. (2015) indicated that increasing nursery centers promotes migrations of the child-raising generation, which is consistent with results in Figs. 6.4 and 6.5. Abe and Harada (2008) also presented an analysis that increasing nursery centers affects birth rates; however, Kamishihoro Town is not yet at that stage, and it is worth following up whether birth rate actually rises going forward. In summary, enhanced parenting support measures by Kamishihoro Town promoted migrations of households with small children from surrounding regions in the initial stage, and may have also prompted migrations from other regions after a slight time lag.

\subsubsection{Analysis of Number of People Moving from Kamishihoro Town, Hokkaido Prefecture}

Next, I will present the number of people moving from Kamishihoro Town, the other factor in the town's social population change. Figure 6.6 shows that the number of people moving from Kamishihoro Town to other regions has been declining since 2014, which is when the amount of donations received by the town started to increase. By region, the number of people moving from Kamishihoro Town to Obihiro City, which used to be the largest portion, was 46 in 2015 (a decrease of 27 from the previous year), and fewer than 10 in 2016, and with this, the number of people moving to the three surrounding regions decreased drastically in 2016 to 37. Similar

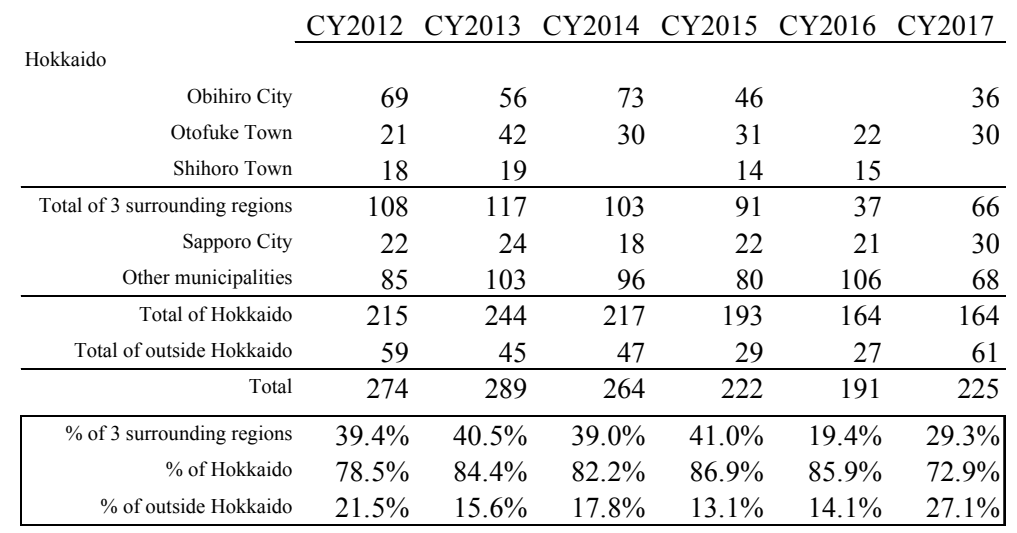

Fig. 6.6 Trend in no. of people moving from Kamishihoro Town, Hokkaido Prefecture. Note The blank spaces for Obihiro City and Shihoro Town do not indicate zero people. Since the MIC database only displays data for migrations of 10 or more people between municipalities, the blank spaces represent unavailable data for migrations of fewer than 10 people. Source Created by the author based on "Basic Resident Register Population Movement Report." 


\begin{tabular}{lrrrrrr} 
& \multicolumn{1}{c}{ CY2012 } & CY2013 & CY2014 & CY2015 & CY2016 & CY2017 \\
\cline { 2 - 7 } 3 surrounding regions & 64 & 78 & 67 & 45 & 20 & 45 \\
$\%$ & $59.3 \%$ & $66.7 \%$ & $65.0 \%$ & $49.5 \%$ & $54.1 \%$ & $68.2 \%$ \\
Other regions & 137 & 132 & 119 & 95 & 123 & 116 \\
$\%$ & $82.5 \%$ & $76.7 \%$ & $73.9 \%$ & $72.5 \%$ & $79.9 \%$ & $72.3 \%$
\end{tabular}

Fig. 6.7 Trend in no. of child-raising generation migrants from Kamishihoro Town, Hokkaido Prefecture. Note The ratio represents the ratio of people under the age of 40 to all people moving from Kamishihoro Town to the respective regions. Source Created by the author based on "Basic Resident Register Population Movement Report."

to the number of people moving to the town, the number settled in 2017 and is slightly reverting to the historical average. As no other major change was detected, it seems outflow to surrounding regions was suppressed.

Similar to aforementioned numbers of people moving to the town, I defined those under the age of 40 as the "child-raising generation," and analyzed the trend in number of people moving to the three surrounding regions and other regions, as shown in Fig. 6.7. In the three surrounding regions, the ratio of child-raising generation migrants declined in terms of both number and ratio in 2015 and 2016, but reverted slightly in 2017. Yet, in the other regions, such significant changes were not detected. In summary, although parenting support measures financed by Hometown Tax Donations seem to suppress outflow to the three surrounding regions, they do not seem to have much impact on suppressing outflow to other regions.

Results revealed that the impact of parenting support measures was different between those considering moving to the three surrounding regions, and to other regions. Basic Research on Social Security and Population Issues (National Institute of Population and Social Security Research, 2016) reported that the main reason for moving to current locations in the past five years was "mainly for housing-related matters (35.4\%)," "work-related matters (12.7\%)," "marriage or divorce (12.0\%)," and "to accompany a family member (7.0\%)." Presumably, residents of Kamishihoro Town moving "mainly for housing-related matters" used to consider moving to the three surrounding regions prior to the implementation of parenting support measures, but started prioritizing moving within the town after such measures were implemented.

As for "work-related matters," which came in second, even if one's workplace changed to Obihiro City, Otofuke Town or Shihoro Town, one does not necessarily have to move, and probably would consider staying in Kamishihoro Town to receive parenting support. On the other hand, if one must move far away because of work relocation, it will be difficult to continue living in Kamishihoro Town just because one wants to receive parenting support. Therefore, although parenting support measures affect those who are considering moving to the three surrounding regions, they do not seem to affect moves to other regions including for job relocations. 


\subsubsection{Summary of Analysis on Kamishihoro Town, Hokkaido Prefecture}

Analysis results unveiled that there was an inflow of households with small children from the surrounding regions in 2015 and 2016, and from distant regions after a slight time lag in 2017. As for impact on settlement, although outflow to the surrounding regions was suppressed in 2015 and 2016, outflow to distant regions was not. Kamishihoro Town decided to allocate all Hometown Tax Donations to the "Dream Fund for Parenting Support and Measures Against Declining Birth Rate" in 2014, and considering the consistency in timing, this may have affected migration and settlement of households with small children to a certain degree.

Impact of a single factor cannot be fully validated since this analysis only verified limited data and population change is affected by various intra-regional factors. However, in view of the hypotheses, the first hypothesis, which suggested that "enhanced parenting support measures financed by Hometown Tax Donations in rural areas generate competition with surrounding municipalities to win over residents," is partly valid; yet it may also be possible that population inflow from surrounding regions ceases once potential migration needs are fulfilled. On another note, in the case of Kamishihoro Town, the number of children attending the free ninte $i$ kodomoen, which was the town's focal initiative, was reaching maximum enrollment.

As for hypothesis (2), which stated that "such measures generate population inflow from urban areas," it seems such measures had impact on some migrations from regions other than the surrounding regions, albeit not only urban areas, after some time. It was also revealed that such measures had a certain impact on promoting settlement of households with small children, as suggested in hypothesis (3). More specifically, measures did not suppress migrations to distant regions, which are presumably mostly work-related, but seemingly served to retain some potential short-distance migrations, by those seeking quality living environments and lifestyles, within the municipality.

On another note, since Kamishihoro Town's initiatives were covered by numerous media, analysis results may have been influenced by such coverage. Without any media coverage, the extent of population inflow and suppression of outflow may not have been so large. In this respect, the increase in migrants from distant regions, as seen particularly in 2017 , requires close attention.

\subsection{Implications for Measures by Rural Areas to Promote Migration and Settlement or Increase Associating Populations}

Analysis results indicated that enhanced parenting support measures financed by Hometown Tax Donations in rural areas may generate competition to win over residents among neighboring regions, although for a short period of time, and propel 
migrations from other regions after some time, while also suppressing potential population outflow to neighboring regions. Therefore, enhancing parenting support measures using Hometown Tax Donations may seem fairly appealing to rural municipalities.

Yet, it is difficult to determine whether disseminating similar measures among many municipalities is effective. This analysis suggested that such measures had certain effects on promoting population inflow from and suppressing potential population outflow to neighboring municipalities. However, if many municipalities follow in Kamishihoro Town's steps, competition for residents between neighboring municipalities will arise, possibly leading to an unwinnable zero-sum game amid nationalscale depopulation. Meanwhile, results were unclear regarding the nationwide challenge of migrations from urban to rural areas. While partial optimization may be achieved on the part of each municipality, total optimization for the country as a whole will most likely not.

Thus, what each municipality should do is strive to increase visitors and interacting populations from distant areas, as seen in the cases presented in the first half of this chapter. The idea is to share people among multiple regions, rather than promote settlement. In terms of work, the spread and active use of teleworking, work sharing and crowdsourcing are desired. To the advantage of rural areas, such movements are gaining momentum especially on the back of the novel coronavirus pandemic.

With respect to increasing visitors, Kamishihoro Town is also actively interacting with private companies, for example, through demonstration trials of self-driving buses and drone life-saving contests. They are also building a rest house within the Naitai Highland Farm as a place for interaction, thereby developing a scheme that does not rely solely on enhanced parenting support measures.

An increasing number of regions are trying to raise interacting populations through deploying or conducting demonstration trials of smart cities, yet such efforts will end in vain if interacting populations disperse after such demonstrations end. Rather than drastically increasing populations through a large-scale measure, it is important to accumulate small yet sure steps to attract non-locals who will endorse the town in the medium to long run, and thereby steadily increase associating and interacting populations. In addition, it will be important to revitalize regions through industrygovernment-banking collaboration, as was discussed in the previous chapter.

\section{References}

Abe K, Harada Y (2008) Impact of parenting support measures on birth rates-municipal data analysis (In Japanese). Audit Study 38:1-16

Abe S, Kondo M, Kondo A (2010) Study on factor analysis and promotion measures of U-, I-, J-turn migrations to rural areas (In Japanese). Infrastruct Plann Manage Study Essays 27:219-230

Hoda T (2019) How to increase associating populations through Hometown Tax Donations (In Japanese). Koumei Mon J 3:38-43 
Hoda T, Kubo Y (2019) Enhancing parenting support measures through Hometown Tax Donationimplications from a case study on Kamishihoro Town, Hokkaido Prefecture (In Japanese). J Econ Bus Admin 219(6):81-96

Komori S (2008) Study on intent of migrants to rural areas and awareness of welcoming sidecase study of mountainous areas in Kyoto prefecture (follow-up) (In Japanese). J Rural Probl 44(1):146-149

Koyanagi S (2016) Background, current state and issues of rural area migration and settlement promotion measures: case studies from the Kyushu area (In Japanese). J Geogr 125(4):507-522

Lee Y, Sugiura H (2017) Determinants of returns to rural areas and promotion measures-from a case study on Hirosaki City, Aomori Prefecture (In Japanese). Financ Rev 131:123-143S

Ministry of Internal Affairs and Communications. Basic Resident Register migration report (2018) — reference table (number of people moving in by age (in age groups of ten years), gender, and address before moving - prefecture. 2012-2017) (In Japanese)

Ministry of Internal Affairs and Communications (2018) Local public finance white paper (In Japanese)

Ministry of Internal Affairs and Communications. Basic Resident Register migration report (2018) - number of people moving in by gender and address before moving (by prefecture, 21 large cities, and other regions-prefecture. 2012-2017) (In Japanese)

Ministry of Internal Affairs and Communications. Basic Resident Register migration report (2018) — reference table (number of people moving out by age (in age groups of ten), gender, and address after moving - prefecture, municipality. 2012-2017) (In Japanese)

Ministry of Internal Affairs and Communications, Population, demographics and number of households based on the Basic Resident Register [Japanese residents] population by municipality and age group (In Japanese)

Nakazawa K, Yaoita S, Yokoyama A (2015) Study on development of social infrastructure and services related to parenting support-consideration of impacts on birth rates and movements of children and of best practices (In Japanese). Financ Rev 124:7-28

Sakuno H (2016) Spread of rural migration and regional measures-perception of "return to countryside" from the side of rural regions (In Japanese). Ann Jpn Assoc Econ Geogr 62(4):324-345

Open Access This chapter is licensed under the terms of the Creative Commons AttributionNonCommercial-NoDerivatives 4.0 International License (http://creativecommons.org/licenses/bync-nd/4.0/), which permits any noncommercial use, sharing, distribution and reproduction in any medium or format, as long as you give appropriate credit to the original author(s) and the source, provide a link to the Creative Commons license and indicate if you modified the licensed material. You do not have permission under this license to share adapted material derived from this chapter or parts of it.

The images or other third party material in this chapter are included in the chapter's Creative Commons license, unless indicated otherwise in a credit line to the material. If material is not included in the chapter's Creative Commons license and your intended use is not permitted by statutory regulation or exceeds the permitted use, you will need to obtain permission directly from the copyright holder.

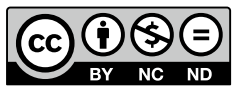

